\title{
BMJ Open Impact of a novel community testing pathway for people with suspected COVID-19 in Wales: a cost- minimisation analysis
}

\author{
Jonny Currie (D) , ${ }^{1}$ James Adamson, ${ }^{1}$ Bethan Bowden, ${ }^{1}$ Julie Woolls, ${ }^{2}$ \\ Rachel Jones, ${ }^{3}$ Brendan Healy, ${ }^{4}$ David Heyburn, ${ }^{1}$ Ananda Giri Shankar, ${ }^{1}$ \\ Robin Howe ${ }^{1}$
}

To cite: Currie J, Adamson J, Bowden B, et al. Impact of a novel community testing pathway for people with suspected COVID-19 in Wales: a cost-minimisation analysis. BMJ Open 2020;10:e038017. doi:10.1136/ bmjopen-2020-038017

- Prepublication history for this paper is available online. To view these files, please visit the journal online (http://dx.doi org/10.1136/bmjopen-2020038017).

Received 25 February 2020 Revised 22 July 2020 Accepted 31 July 2020

Check for updates

(c) Author(s) (or their employer(s)) 2020. Re-use permitted under CC BY-NC. No commercial re-use. See rights and permissions. Published by BMJ.

${ }^{1}$ Public Health Wales, Cardiff, UK ${ }^{2}$ University Hospital of Wales Healthcare NHS Trust, Cardiff, UK

${ }^{3}$ Public Health Wales

Microbiology Swansea,

Singleton Hospital, Swansea, UK ${ }^{4}$ University Hospital Wales Heath Park, Cardiff, UK

Correspondence to

Dr Jonny Currie;

jonny.currie@wales.nhs.uk

\section{ABSTRACT}

Objective To compare National Health Service (NHS) organisations' testing pathways for patients with suspected COVID-19 in the community versus standard hospital testing practices.

Perspective NHS commissioners and services.

Methods During the containment phase of the COVID-19 pandemic we developed a community model pathway for COVID-19 testing in Wales with testing teams undertaking swabbing for COVID-19 in individuals' usual place of residence. We undertook a cost-minimisation analysis comparing the costs to the NHS in Wales of community testing for COVID-19 versus standard hospital testing practices and ambulance conveyancing. We analysed data from patients with suspected COVID-19 between January and February 2020 and applied assumptions of costs from national contractual and reference costs for ambulances, staffing and transportation with market costs at the time of publication.

Results 177 patients with suspected COVID-19 underwent community testing via local NHS organisations between January and February 2020 with a mean age of 46.1 (IQR 27.5-56.3). This was $92 \%$ of total patients who were tested for COVID-19 during this period. We estimate, compared with standard hospital testing practices, cash savings in improved productivity for the NHS of $£ 24,539$ during this time period, in addition to further nonmonetised benefits for hospital and ambulance flow. Conclusions Community testing for COVID-19 in Wales is now an established pathway and continues to bring benefits for patients, local healthcare organisations and the NHS. Further application of this model in other settings and to other infectious diseases may herald promising returns.

\section{BACKGROUND}

\section{Context}

On 30 January 2020, following burgeoning cases in China and other countries, the WHO declared the outbreak of novel coronavirus (2019-nCoV, hereafter 'COVID-19') a public health emergency of international concern. In preparation for the first case in Wales, the
Strengths and limitations of this study

- Wales implemented in the initial phase of the pandemic a novel community testing model for patients with suspected COVID-19 with clear benefits for hospital flow.

- This study suggests there were significant positive resource implications of implementing this model compared with then standard practice of conveying all patients for testing in hospital.

- Wider benefits for patient experience and potential avoidance of healthcare transmission of COVID-19 during hospital transfer may also be realised by this model.

- Data availability on staffing costs and a focus on the healthcare provider perspective are key limitations of this study.

- Further research is needed to evaluate this model for wider outcomes against standard practices.

National Health Service (NHS) and public health agencies in Wales invested in systems to ensure robust case management and infection control measures in anticipation for transmission to Welsh residents; a statement from the Chief Medical Officer (CMO) for Wales following the WHO announcement on 31 January 2020 summarised actions being taken in Wales and across the UK to ensure preparedness for anticipated transmission and spread. ${ }^{2}$

The Welsh health protection system and Prudent Healthcare

The landscape and nature of health protection systems in Wales bears both similarities and differences to those of its neighbouring devolved nations of the UK and in other countries. Health protection teams (HPT), like others internationally, work with local frontline healthcare professionals in primary and secondary care settings in the management 


\section{Box 1 Prudent Healthcare principles in Wales}

Prudent Healthcare principles ${ }^{4}$

Prudent principle 1

Achieve health and well-being with the public, patients and professionals as equal partners through coproduction.

Prudent principle 2

Care for those with the greatest health need first, making most effective use of all skills and resources.

Prudent principle 3

Do only what is needed - no more, no less—and do no harm.

Prudent principle 4

Reduce inappropriate variation using evidence-based practices consistently and transparently.

of notifications of infectious diseases of public health concern and in coordinating actions relating to incidents or outbreaks of communicable disease. Wales has a single All-Wales Health Protection Service covering the approximate 3.1 million residents spread across $20782 \mathrm{~km}^{2}$, a unified Public Health Microbiology Division covering the majority of microbiology laboratories across Wales, a national Communicable Disease Surveillance Centre providing specialist epidemiological intelligence and support, and integrated local health boards with responsibility for population health and healthcare service delivery. These functions, alongside support from the devolved administration in Welsh Government and close partnership with front-line clinicians, have allowed for the development of an agile health protection system in Wales able to respond to, and innovate in the face of, significant public health challenges.

The NHS in Wales has, since 2014, endeavoured to deliver prudent healthcare: a concept developed first by the Bevan Commission ${ }^{4}$ and at the heart of Welsh Government's plans for health and social care in A Healthier Wales. ${ }^{5}$ Prudent Healthcare (see box 1) aims to deliver healthcare equitably and through coproduction, avoiding inappropriate variation while maximising the use of skills in resources. As part of this strategy care delivered closer to home through integrated health and care services has been emphasised as key, ${ }^{4}$ moving the focus away from historic reliance on hospitals as the key delivery agent of healthcare in Wales.

\section{Development of a novel community testing pathway for COVID-19}

Prior to the $\mathrm{WHO}^{1}$ and UK CMO's ${ }^{2}$ announcements in January 2020, the Health Protection and Microbiology Divisions in Public Health Wales (PHW) developed a novel community testing pathway to enable people suspected as having COVID-19 to be tested in the community, avoiding pressure on ambulance and hospital services. ${ }^{6}$ Implementation of this pathway enabled over $90 \%$ of people with suspected COVID-19 to be tested in the community. We describe here the methods of developing this testing model and the economic implications for the healthcare system in terms of costs and services avoided, comparing our model to usual practices of care around the UK.

\section{METHODS}

Pathway

Public Health England developed guidance for the epidemiological and clinical risk assessment of people suspected to have COVID-19 which was applied in Wales. ${ }^{7}$ Decision to test a suspected case in Wales was made through a tripartite conversation between the HPT, microbiology with reference to the clinical assessment of the notifying healthcare professional (see figure 1). If clinical assessment indicated that hospital admission was not required, all possible cases of COVID-19 were entered into the community testing pathway. The first stage of this pathway involved a public health assessment by the HPT. Using a call centre model at PHW hubs across Wales, call advisors undertook a public health assessment, providing isolation advice and following completion of a minimum data set requested COVID-19 sampling by microbiology colleagues.

On receipt of the request for swabbing, community testing was initially undertaken by infectious diseases and microbiology colleagues, trained in appropriate personal protective equipment (PPE). Community testing required two trained individuals with appropriate PPE attending the home of the suspected case. Donning and doffing of PPE was performed in a safe environment prior to obtaining the required swabs. The samples were then couriered, in appropriate packaging and condition, by prior arrangement to the University Hospital of Wales laboratory in Cardiff, Wales.

This pathway was initially developed by the PHW Microbiology Division in response to first suspected cases in Wales. As scale of suspected cases increased a protocol was developed by PHW to enable local health boards to deliver this model. Local health board staff were trained in appropriate PPE usage and deployed within Local Health Boards to create community testing teams. Referral from PHW of suspected cases was allocated by geographical area to the appropriate LHB who activated their community testing team to undertake sampling within the home environment of a suspected case. Results were returned to PHW who delivered them directly to individuals. At the stage of analysis no positive cases had been returned within Wales.

\section{Data collection}

Data on numbers of people tested and their demographic and epidemiological information were maintained on a data set held by the PHW Microbiology Division. This data set additionally collated information on time to test, time to result, the result of common respiratory pathogen screen and reference laboratory results. We report here on data collected between 17 January and 17 February 2020, excluding cases for which there was no sample collected $(n=3)$ or no postcode recorded $(n=4)$. 


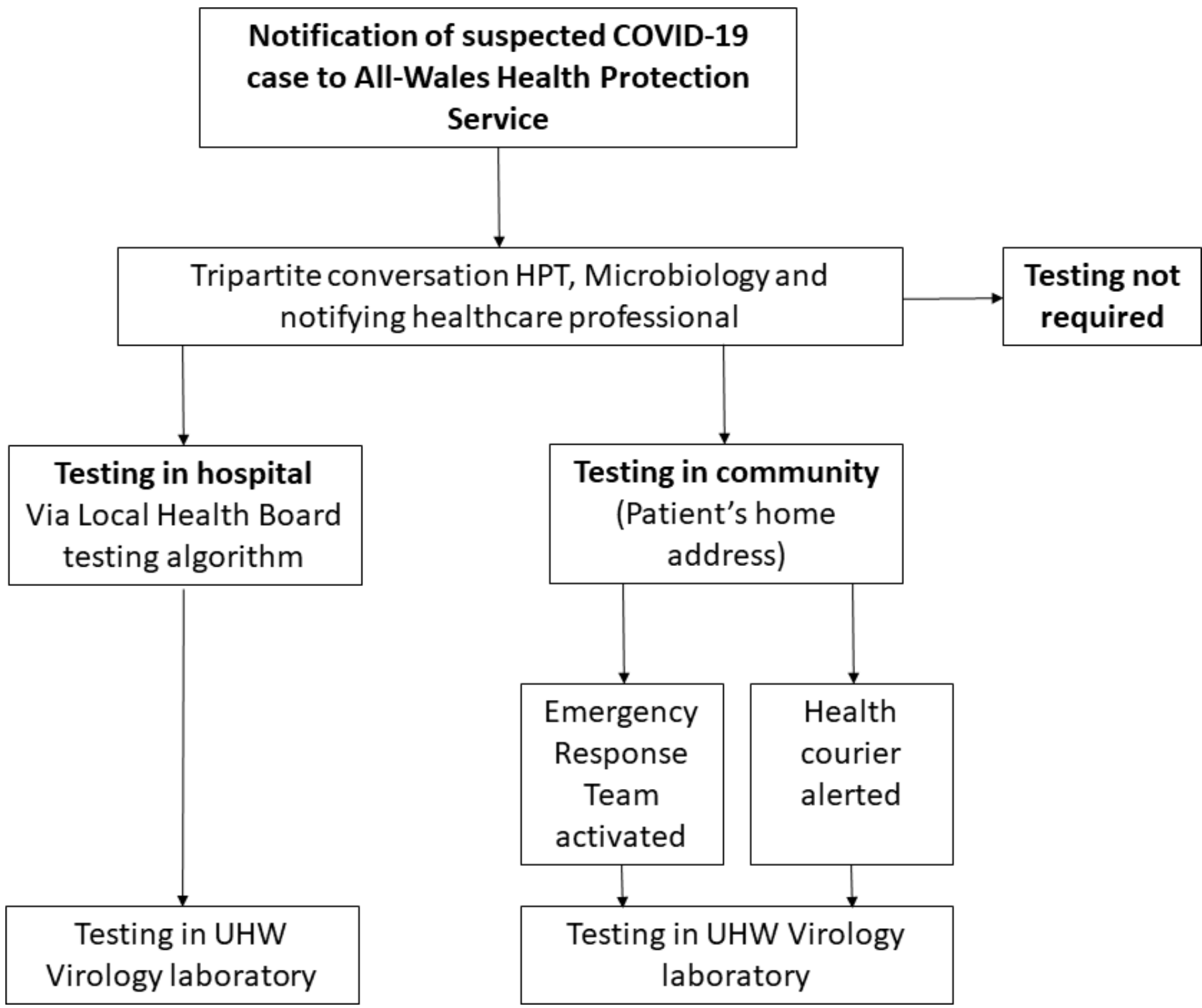

Figure 1 Summary flow chart of the COVID-19 community testing pathway in Wales. HPT, health protection team; UHW, University Hospital Wales.

\section{Data analysis}

We undertook a cost-minimisation analysis ${ }^{8}$ on the assumption that there was no significant difference in outcome of testing people with suspected COVID-19 in the community versus usual hospital care. Due to available data, we focus exclusively on the perspective of the health service provider and on health service costs and used then contemporary market prices. We did not apply discounting in our analysis. We made a number of assumptions in our modelling including that community testing was performed by health board staff travelling to patients' homes and that all community testing team journeys were round trips, starting and ending at the health board's headquarters address, with a mileage rate of $£ 0.45$ per mile. Courier costs to transport the test sample(s) from the patient's home address to the PHW Virology Laboratory in University Hospital Wales (UHW) in Cardiff were based on $£ 54$ staff costs (half a day per delivery) plus a one-way mileage rate of $£ 0.45$ per mile. Fuel and mileage rates were taken from the Department of Health's Reference Costs, ${ }^{9}$ NHS Terms and Conditions of Service Handbook, ${ }^{10}$ and Agenda for Change Guidance, ${ }^{11}$ respectively. The cost to take a patient to hospital was set at $£ 153$ per hour by the Welsh Ambulance NHS Service Trust (WAST) at the time of the comparison and WAST dispatched two ambulances for each patient collection, equating to four ambulance trips per test in hospital. This was to ensure the patient was conveyed to hospital without interruption and to ensure adequate infection control and decontamination practices in the eventuality of one ambulance experiencing a technical problem. For these comparisons, it was assumed that all ambulances would have travelled to the patient's home address from the nearest COVID-19 designated hospital in that health board and back to the same hospital for testing. Finally, it was assumed that patient collection and loading took 
Table 1 Descriptive statistics for cases of suspected COVID-19 in Wales, January to February 2020, by site of testing

\begin{tabular}{llllr} 
& \multicolumn{2}{l}{ Gender distribution } & & \\
\cline { 2 - 3 } & Male (\%) & Female (\%) & Median age (IQR) & Total (n) \\
\hline Home & $86(48.6)$ & $91(51.4)$ & $46.1(27.5-56.3)$ & 177 \\
Hospital & $7(53.8)$ & $6(46.1)$ & $29.8(22.5-61.6)$ & 13 \\
Primary care & $1(50)$ & $1(50)$ & $23.8(21.2-26.3)$ & 2 \\
Total $(\mathrm{n})$ & $94(49)$ & $98(51)$ & & 192 \\
\hline
\end{tabular}

20 min before returning to hospital and that the costs of staffing and consumables such as PPE would broadly be comparable between pathways.

All distances and trip times were calculated in Google Maps using postcodes as starting points and end destinations, with the shortest distance option being selected. The journey time for ambulance trips was recorded at the same time as distance calculation.

For each health board, the total, average, maximum and minimum distances were calculated based on 173 unique trip records where home postcode was known. From these data, corresponding costs were calculated. Finally, total and comparative costs were calculated per health board and for all journeys made in Wales using home testing and ambulance transport methods.

We performed the analysis in Microsoft Excel and RStudio V.1.1.419. ${ }^{12}$

\section{RESULTS}

\section{Descriptive statistics}

One hundred and ninety-five cases of suspected COVID-19 were notified to the Health Protection Service in Wales between 17 January and 17 February 2020, of which there were no positive virology results for the SARS-CoV-2 virus. Table 1 summarises the descriptive epidemiological and demographic statistics for this cohort; $92.2 \%$ of cases during this period were tested at home, with the majority $(73.4 \%)$ tested and reported within 24 hours.

\section{Cost-minimisation analysis}

The findings from the cost-minimisation analysis are presented in tables 2-4. For the 173 cases of suspected COVID-19 whose test data were used in this analysis, the estimated savings were £24539 in resources freed for other services, driven by the absence of requiring conveyancing people with suspected COVID-19 to hospital via ambulance, while still requiring a means of transporting staff and the sampling kit to people's homes and onward to hospital laboratories.

\section{DISCUSSION}

\section{Summary of findings}

The total cost of community testing in Wales was $£ 7752$ for 173 tests (£44.81 per test); this would have been $£ 34291$ if the ambulance to hospital method had been used (£198.21 per test) or $£ 17145$ using a more conservative model involving only one ambulance. The total mileage for conducting the 173 tests via the community testing method was 17106 miles (10399 courier miles and 6707 community testing team miles). The average community testing round trip for all tests was 37.4 miles and the average courier distance per test was 55.6 miles. The total

Table 2 Output from cost-minimisation analysis of home testing pathway for COVID-19

\section{Community testing}

\begin{tabular}{|c|c|c|c|c|c|c|c|c|}
\hline Area & Tests (n) & $\begin{array}{l}\text { Maximum } \\
\text { distance }\end{array}$ & $\begin{array}{l}\text { Minimum } \\
\text { distance }\end{array}$ & $\begin{array}{l}\text { Average } \\
\text { distance }\end{array}$ & $\begin{array}{l}\text { Total } \\
\text { distance* }\end{array}$ & $\begin{array}{l}\text { Total cost } \\
\text { (£) }\end{array}$ & $\begin{array}{l}\text { Average } \\
\text { cost per } \\
\text { mile (£) }\end{array}$ & $\begin{array}{l}\text { Average } \\
\text { cost per test } \\
\text { (£) }\end{array}$ \\
\hline ABUHB & 23 & 118 & 12 & 42 & 972 & 491 & 1.07 & 21.37 \\
\hline BCUHB & 43 & 434 & 133 & 249 & 10702 & 4870 & 0.71 & 113.26 \\
\hline CTMUHB & 27 & 86 & 12 & 37 & 998 & 503 & 1.18 & 18.63 \\
\hline CAVUHB & 41 & 71 & 4 & 17 & 709 & 373 & 1.45 & 9.09 \\
\hline SBUHB & 26 & 117 & 43 & 68 & 1767 & 849 & 0.73 & 32.67 \\
\hline Wales & 173 & - & - & 94 & 17106 & 7752 & 0.75 & 44.81 \\
\hline
\end{tabular}

*Shortest distance to travel

ABUHB, Aeurin Bevan University Health Board; BCUHB, Betsi Cadwaladr University Health Board; CAVUHB, Cardiff and Vale University Health Board; CTMUHB, Cwm Taf Morgannwg University Health Board; HDUHB, Hywel Dda University Health Board

; SBUHB, Swansea Bay University Health Board. 
Table 3 Output from cost-minimisation analysis of hospital testing for COVID-19 (two ambulances dispatched)

\section{Ambulance to hospital testing-two ambulances}

\begin{tabular}{|c|c|c|c|c|c|c|c|c|}
\hline Area & Tests (n) & $\begin{array}{l}\text { Maximum } \\
\text { distance }\end{array}$ & $\begin{array}{l}\text { Minimum } \\
\text { distance }\end{array}$ & $\begin{array}{l}\text { Average } \\
\text { distance }\end{array}$ & $\begin{array}{l}\text { Total } \\
\text { distance** }\end{array}$ & $\begin{array}{l}\text { Total cost } \\
\text { (£) }\end{array}$ & $\begin{array}{l}\text { Average } \\
\text { cost per } \\
\text { mile (£) }\end{array}$ & $\begin{array}{l}\text { Average } \\
\text { cost per } \\
\text { test }(£)\end{array}$ \\
\hline ABUHB & 23 & 100 & 2 & 30 & 700 & 4204 & 6.01 & 182.79 \\
\hline BCUHB & 43 & 262 & 2 & 39 & 1678 & 8018 & 4.78 & 186.47 \\
\hline \multirow[t]{2}{*}{ CTMUHB } & 27 & 72 & 6 & 41 & 1102 & 5693 & 5.17 & 210.85 \\
\hline & 41 & 58 & 6 & 22 & 900 & 7469 & 8.30 & 182.17 \\
\hline SBUHB & 26 & 81 & 8 & 32 & 839 & 5128 & 6.11 & 197.24 \\
\hline Wales & 173 & - & - & 43 & 6396 & 34291 & 5.36 & 198.21 \\
\hline
\end{tabular}

*Shortest distance to travel

ABUHB, Aneurin Bevan University Health Board; BCUHB, Betsi Cadwaladr University Health Board; CAVUHB, Cardiff and Vale University Health Board; CTUHB, Cwm Taf University Health Board; HDUHB, Hywel Dda University Health Board; SBUHB, Swansea Bay University Health Board.

mileage using the ambulance to the nearest designated COVID-19 hospital method would have been 6396 miles. This would have been 3198 miles if one ambulance had been used per patient. The average round trip to hospital for all tests would have been 21.6 miles. This equates to a cost of $£ 0.75$ per mile and $£ 5.36$ per mile for community and hospital testing, respectively. The high courier mileage reflects the fact that all samples were tested in UHW, Cardiff.

For community testing, the lowest average cost per test was $£ 9.09$ (Cardiff and Vale University Health Board (CAVUHB) ) and the highest was £113.17 (Betsi Cadwaladr University Health Board (BCUHB)). Conversely, the lowest average cost per mile was $£ 0.72$ (BCUHB) and the highest was $£ 1.45$ (CVUHB). Both of these metrics reflect the differences between the smaller area and colocation of the PHW Virology Laboratory in CVUHB versus the larger area and further distance to the Virology
Laboratory in BCUHB. For hospital testing, the lowest average cost per test would have been $£ 182.79$ (Aneurin Bevan University Health Board) and the highest average test per cost would have been $£ 290.63$ (Hywel Dda University Health Board).

This study has presented a novel approach to testing people in the community with suspected COVID-19 deemed by risk assessment as suitable for home testing. We estimate the development and implementation of this pathway resulted in savings in 1 month alone of $£ 24539$. Wider benefits of this pathway in an acute winter period during which pressures on the NHS in Wales are high include the freeing of healthcare and ambulance resources to serve other patients and an improved patient experience given the availability of testing in people's own homes.

Table 4 Output from cost-minimisation analysis of hospital testing for COVID-19 (one ambulance dispatched)

Ambulance to hospital testing-one ambulance

\begin{tabular}{|c|c|c|c|c|c|c|c|c|}
\hline Area & Tests (n) & $\begin{array}{l}\text { Maximum } \\
\text { distance }\end{array}$ & $\begin{array}{l}\text { Minimum } \\
\text { distance }\end{array}$ & $\begin{array}{l}\text { Average } \\
\text { distance }\end{array}$ & $\begin{array}{l}\text { Total } \\
\text { distance }{ }^{\star * *}\end{array}$ & $\begin{array}{l}\text { Total cost } \\
\text { (£) }\end{array}$ & $\begin{array}{l}\text { Average } \\
\text { cost per } \\
\text { mile (£) }\end{array}$ & $\begin{array}{l}\text { Average } \\
\text { cost per } \\
\text { test }(£)\end{array}$ \\
\hline ABUHB & 23 & 50 & 1 & 15 & 350 & 2102 & 3.00 & 91.40 \\
\hline BCUHB & 43 & 131 & 1 & 20 & 839 & 4009 & 2.39 & 93.24 \\
\hline CTMUHB & 27 & 36 & 3 & 20 & 551 & 2846 & 2.58 & 105.42 \\
\hline SBUHB & 26 & 41 & 4 & 16 & 420 & 2564 & 3.06 & 98.62 \\
\hline Wales & 173 & - & - & 21 & 3198 & 17145 & 2.68 & 99.11 \\
\hline
\end{tabular}

*Shortest distance to travel

ABUHB, Aneurin Bevan University Health Board; BCUHB, Betsi Cadwaladr University Health Board; CAVUHB, Cardiff and Vale University Health Board; CTMUHB, Cwm Taf University Health Board; HDUHB, Hywel Dda University Health Board; SBUHB, Swansea Bay University Health Board. 


\section{Comparison to other outbreaks and regions}

We are aware of colleagues in other areas implementing similar pathways for high-consequence infections such as COVID-19 involving community risk assessment and testing. North West London NHS Trust reported community testing of 130 people over 2 weeks in early 2020 for people with suspected COVID-19, ${ }^{13}$ while health protection services in Scotland are continuing to explore delivery of such a model where appropriate. ${ }^{14}$ We are not aware, however, in the UK or overseas of a similar scale of community home testing for COVID-19, and believe if scaled elsewhere this model could yield improved outcomes for patient experience and allocative efficiency for healthcare providers and planners. Further, the achievement of this model across rural geographies such as are typical in Wales does we believe further strengthen the potential for implementation both in other parts of the UK and in other contexts internationally.

\section{Limitations}

Our analysis contains several limitations relevant for comparisons in other areas. The costing model does not consider staff time; most community testing was undertaken in staff pairs, which can be considered commensurate with ambulance staff on the same pay band.

The community testing model resulted in far greater mileage than the ambulance method, which should be a consideration from an environmental perspective. No consideration was given to carbon dioxide emissions for each method, but health boards in Wales are duty bound to consider this as part of their carbon reduction strategies.

Trip times for ambulance to hospital method were taken at the time of calculating route distance on Google Maps. This might not have reflected actual trip times due to traffic conditions at the time of the test. However, trip times were representative of an average speed of $30 \mathrm{mph}$, which is not unreasonable.

Of the 173 home tests conducted, a total of 36 were performed at the same time for patients at the same address across all health boards; no adjustments were made for these tests, but doing so would make community testing more efficient still.

Our sample size was relatively small particularly in drawing comparisons to the hospital and primary carebased testing and we were unable to perform any sensitivity analyses to explore ranges of economic outcomes due to available data. Finally, while our surveillance did not identify any unintended consequences for patient or public health outcomes, we acknowledge the constraints in undertaking analysis of a pathway implemented outside of controlled trial settings, though the prospects of doing this mid-incident would naturally be challenging.

\section{CONCLUSIONS}

While the use of a community testing model resulted in 2.67 times the mileage by staff in Wales compared with the use of ambulances and local hospitals in a single month, the cost of delivering the tests was more than four times cheaper. An advantage of the community testing model was the ability to transport multiple test samples from one address, whereas ambulances would not have been able to transport multiple patients to hospital. It is important to note that the community testing model would have been comparatively cheaper still had testing been available at more local hospitals.

Our model for community testing for COVID-19 in Wales has, we believe, been demonstrated to be of significant economic benefit to the NHS in Wales and delivers on the principles of Prudent Healthcare, by maximising the use of available healthcare resources. PHW and local health boards will continue to collaborate closely in the application of this model and believe it holds promise as a novel approach in the case management and control of communicable diseases in Wales and other countries.

\section{Twitter Jonny Currie @jonnycurrie}

Contributors JC, JA and BB drafted and revised the manuscript. JA undertook the economic analysis including estimations of distance travelled for journeys by health board. JC as lead author is the guarantor. JW, RJ and BH were consulted on the paper and provided revision recommendations. JW and a wider team from Public Health Wales Microbiology produced the initial community testing pathway document referenced in the paper. $\mathrm{RH}$ provided the data set for analysis and provided revision recommendations. DH provided costing data for the economic analysis and provided revision recommendations. AGS oversaw the study as supervisor.

Funding The authors have not declared a specific grant for this research from any funding agency in the public, commercial or not-for-profit sectors.

\section{Competing interests None declared.}

Patient and public involvement Patients and/or the public were not involved in the design, or conduct, or reporting, or dissemination plans of this research.

Patient consent for publication Not required.

Provenance and peer review Not commissioned; externally peer reviewed.

Data availability statement Data are available in a public, open access repository. Extra data can be accessed via the Dryad data repository at http://datadryad.org/ with the doi: 10.5061/dryad.79cnp5hsp.

Open access This is an open access article distributed in accordance with the Creative Commons Attribution Non Commercial (CC BY-NC 4.0) license, which permits others to distribute, remix, adapt, build upon this work non-commercially, and license their derivative works on different terms, provided the original work is properly cited, appropriate credit is given, any changes made indicated, and the use is non-commercial. See: http://creativecommons.org/licenses/by-nc/4.0/.

\section{ORCID iD}

Jonny Currie http://orcid.org/0000-0003-1563-9854

\section{REFERENCES}

1 World Health Organization. Statement on the second meeting of the International health regulations (2005) emergency Committee regarding the outbreak of novel coronavirus (2019-nCoV). Available: https://www.who.int/news-room/detail/30-01-2020-statementon-the-second-meeting-of-the-international-health-regulations-( 2005)-emergency-committee-regarding-the-outbreak-of-novelcoronavirus-(2019-ncov) [Accessed 18 Feb 2020].

2 Welsh Government. Statement from the chief medical officer for Wales about coronavirus (2019-nCoV), 2020. Available: https://gov. wales/statement-chief-medical-officer-wales-about-coronavirus2019-ncov [Accessed 18 Feb 2020].

3 Welsh Government. Wales geography. A guide to Wales, 2020. Available: https://www.wales.com/about/location-climate/find-yourbearings [Accessed 19 Feb 2020]. 
4 Bevan Commission. Prudent healthcare - the provisional principles, 2014. Available: http://www.bevancommission.org/en/prudenthealthcare [Accessed 19 Feb 2020].

5 Welsh Government. A healthier Wales: our plan for health and social care, 2019. Available: https://gov.wales/healthier-wales-long-termplan-health-and-social-care [Accessed 18 Feb 2020].

6 Woolls J, Howe R, Public Health Wales Microbiology Division. Guidance for clinicians collecting, transporting and waste management of HCID respiratory virus 2019-nCoV specimen(s) in the community, 2020. Available: https://phw.nhs.wales/topics/ novel-coronavirus/guidance-for-clinicians-collecting-transportingand-waste-management-of-a-hcid-respiratory-virus-2019-ncovspecimen-s-in-the-community/ [Accessed 18 Feb 2020].

7 Public Health England. COVID-19: investigation and initial clinical management of possible cases. Available: https://www.gov. uk/government/publications/wuhan-novel-coronavirus-initialinvestigation-of-possible-cases/investigation-and-initial-clinicalmanagement-of-possible-cases-of-wuhan-novel-coronavirus-wncov-infection [Accessed 18 Feb 2020].

8 Robinson R. Costs and cost-minimisation analysis. BMJ 1993;307:726-8.
9 Department of Health. Reference Costs 2015-16. December, 2016. Available: https://assets.publishing.service.gov.uk/government/ uploads/system/uploads/attachment_data/file/577083/Reference Costs_2015-16.pdf [Accessed 19 Feb 2020].

10 NHS Employers. NHS terms and conditions of service Handbook. Part 3: terms and conditions of service. section 17: reimbursement of travel costs. Available: https://www.nhsemployers.org/tchandbook/ part-3-terms-and-conditions-of-service/section-17-reimbursementof-travel-costs [Accessed 19 Feb 2020].

11 NHS Employers. NHS terms and conditions (AfC) pay scales 2019/20. Available: https://www.nhsemployers.org/pay-pensionsand-reward/agenda-for-change/pay-scales [Accessed 19 Feb 2020].

12 RStudio Team. RStudio: integrated development for R. Boston, MA: RStudio, Inc, 2015.

13 Mahase E. Coronavirus: home testing pilot launched in London to cut Hospital visits and ambulance use. BMJ 2020;368:m621.

14 Scottish Government. Coronavirus testing. Scottish facilities deliver quicker results, 2020. Available: https://www.gov.scot/news/ coronavirus-testing [Accessed 19 Feb 2020]. 